\title{
Unusual case of intercoronary communication
}

\author{
Anandbir Bath, ${ }^{\oplus 1}$ Mishita Goel, ${ }^{2}$ Sourabh Aggarwal, ${ }^{2}$ Vishal Gupta ${ }^{2}$
}

${ }^{1}$ Internal Medicine, Western Michigan University Homer Stryker MD School of Medicine, Kalamazoo, Michigan, USA ${ }^{2}$ Interventional Cardiology, Ascension Borgess Medical Center, Kalamazoo, Michigan, USA

\section{Correspondence to}

Dr Anandbir Bath,

bathanand@gmail.com,

anandbir.bath@med.wmich.edu

Accepted 27 April 2019

\section{DESCRIPTION}

A 53-year-old man with history of coronary artery disease (CAD) status after percutaneous coronary intervention of left anterior descending (LAD), diabetes mellitus type II and dyslipidaemia presented to our cardiology clinic with exertional, episodic chest pain and palpitations. His physical examination was normal with a blood pressure of $136 / 80 \mathrm{~mm} \mathrm{Hg}$ and a regular heart rate of $76 / \mathrm{min}$. He underwent stress test where his baseline ECG was normal but his stress ECG showed non-sustained ventricular tachycardia with myocardial perfusion imaging revealing a reversible defect involving the inferior wall. Coronary angiography showed patent stents in proximal and mid-LAD without any in-stent restenosis. There was no evidence of obstructive CAD in LAD and left circumflex artery (LCX)(figure 1A-B). However, he was noted to have a retrograde filling of the LCX from right coronary artery (RCA) (figure 2A-B). Previous angiography reports did not describe the retrograde filling. Since the distal end of the retrograde filling was not definitely visualised, it was decided to do simultaneous dual injections which revealed intercoronary communication (ICC) between the right posterolateral (RPL) and the LCX (figure 2B).

ICC is a rare congenital anomaly, involving anastomosis between two non-obstructed coronary arteries, which was first described in $1972 .{ }^{1}$ The most common type of ICC is between RCA and LCX, as noted in our case. ${ }^{2}$ These anomalies, also known as coronary arcade, are encountered in $0.05 \%$ of all the diagnostic coronary angiographies. ${ }^{34}$ In one study, the incidence was reported to be as low as $0.002 \% .^{5}$ The histological cross sections reveal well-defined muscular layer which resembles an epicardial coronary artery. ICC should be differed from coronary collaterals which are formed in the setting of obstructive CAD. The vessels involving the ICC are usually single, straight, extramural and larger in diameter $(\geq 1 \mathrm{~mm})$ as compared with coronary collaterals, which are multiple, non-terminal and smaller in diameter. Also, the histological sections of coronary collaterals reveal poorly

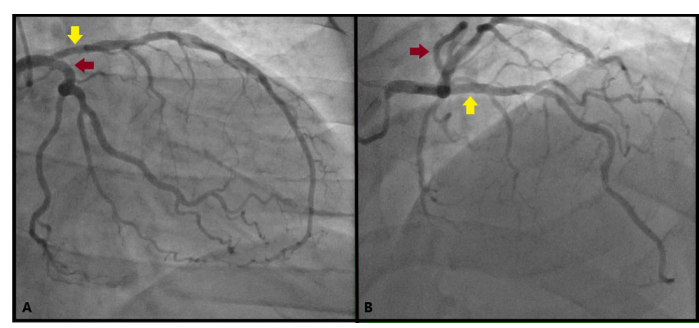

Figure 1 Left anterior descending (yellow arrow) and left circumflex artery (red arrow).

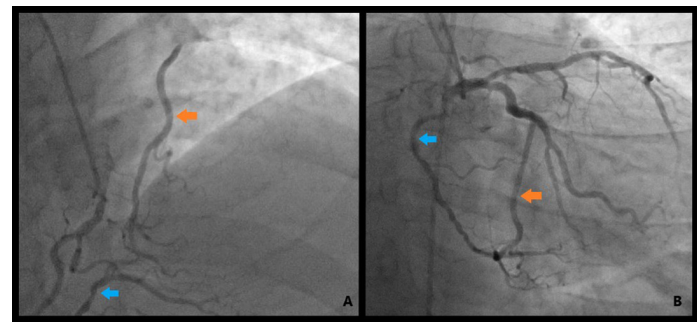

Figure 2 (A) ICC (orange arrow) arising from right coronary artery (blue arrow). (B) Simultaneous dual injection of left and right coronary arteries revealing bidirectional ICC (orange arrow) between the right coronary artery (blue arrow) and the left circumflex artery. ICC, intercoronary communication .

organised collagen and muscle fibres supporting endothelium. The functional significance of ICC depends on the direction of blood flow, which can be unidirectional or bidirectional with the ability to supply blood to the myocardium at risk in the setting of stenosis. ${ }^{6}$ On the contrary, these can be a cause of myocardial ischaemia due to coronary steal phenomenon. Owing to the larger diameter, they can also serve as a better guide during intervention of the occluded coronaries. ${ }^{7}$ We believe that ICC between the RPL and the LCX in our patient was of congenital origin given the distinctive angiographic features (single, straight and large diameter). As there was no significant obstructive CAD noted on the angiogram, the changes noted on stress ECG and myocardial perfusion imaging can be attributed to the coronary steal phenomenon from ICC, being induced in the situations of heightened stress.

\section{Learning points}

The rare occurrence of intercoronary communication (ICC) is known in patients with and without coronary artery obstruction.

- Awareness of these rare channels, their possible locations and distinct morphology from collaterals will help cardiologists in making correct diagnosis and thus, needs to be reported to determine its true prevalence.

- Congenitally present ICCs should be differed from coronary collaterals. Smaller, multiple and non-terminal vessels should raise the suspicion for the latter.

Contributors MG: first draft of the manuscript; $A B$ : editing and revision; SA: Interventional Cardiology fellow involved in case. First Review. VG: Interventional Cardiology Attending. Final review. 
Images in...

Funding The authors have not declared a specific grant for this research from any funding agency in the public, commercial or not-for-profit sectors.

Competing interests None declared.

Patient consent for publication Obtained.

Provenance and peer review Not commissioned; externally peer reviewed.

\section{REFERENCES}

1 Cheng TO. Arteriographic demonstration of intercoronary arterial anastomosis in a living man without coronary artery disease. Angiology 1972;23:76-88.
2 Carangal VP, Dehmer GJ. Intercoronary communication between the circumflex and right coronary arteries. Clin Cardiol 2000;23:125-6.

3 Hines BA, Brandt PW, Agnew TM. Unusual intercoronary artery communication: a case report. Cardiovasc Intervent Radiol 1981:4:259-63.

4 Shashanka C, Rajasekhar D, Vanajakshamma V, et al. A rare coronary anomaly: Intercoronary communication between the circumflex and right coronary arteries. Journal of Indian College of Cardiology 2012;2:167-9.

5 Yamanaka 0, Hobbs RE. Coronary artery anomalies in 126,595 patients undergoing coronary arteriography. Cathet Cardiovasc Diagn 1990;21:28-40.

6 Esente P, Gensini GG, Giambartolomei A, et al. Bidirectional blood flow in angiographically normal coronary arteries. Am J Cardiol 1983:51:1237-8.

7 Gupta MD, Girish MP, Tyagi S. Open-ended coronary circulation: innocent bystander or a road map for intervention? Interv Cardiol 2011:3:315-20.

Copyright 2019 BMJ Publishing Group. All rights reserved. For permission to reuse any of this content visit

https://www.bmj.com/company/products-services/rights-and-licensing/permissions/

BMJ Case Report Fellows may re-use this article for personal use and teaching without any further permission.

Become a Fellow of BMJ Case Reports today and you can:

- Submit as many cases as you like

- Enjoy fast sympathetic peer review and rapid publication of accepted articles

- Access all the published articles

Re-use any of the published material for personal use and teaching without further permission

For information on Institutional Fellowships contact consortiasales@bmjgroup.com

Visit casereports.bmj.com for more articles like this and to become a Fellow 